\title{
META-HEURISTICS TECHNIQUES IN CLOUD COMPUTING: APPLICATIONS AND CHALLENGES
}

\author{
Manoj Kumar \\ Research Scholar, CSE Department, DCR University of Science and Technology, \\ Murthal, Sonepat, Haryana, 12201, India \\ manojsarasyiya@gmail.com \\ Suman \\ Professor, CSE Department, DCR University of Science and Technology, \\ Murthal, Sonepat, Haryana, 12201, India \\ suman.cse@drcustm.org
}

\begin{abstract}
Cloud computing has emerged as highly demanding technology in recent years. The transformation of data and services towards cloud has reduced the increased expenditure on hardware and software in the market. The integration of cloud with many technologies like mobile, Internet of Things, etc. has brought new challenges in cloud computing. Researchers have applied various swarm intelligence, nature inspired, and hybrid algorithms to find a pare-to optimal solution for them. State of art optimization algorithms that are applied in solving these problems is presented in this paper. The applications of these algorithms in load balancing, scheduling, resource allocation, virtual machine allocation, and placement have been discussed and analyzed in cloud computing. The impact of these algorithms on quality of service is also analyzed to present some valuable suggestion.
\end{abstract}

Keywords: Cloud Computing, swarm intelligence, nature inspired, virtual machine, scheduling,

\section{Introduction}

Cloud computing is not a new term for IT professionals, industries, and academicians. It leads to the extension of new paradigm like mobile cloud, fog computing, edge computing, Internet of Things (IoT), and Internet of Vehicles (IoV). The applications of cloud computing in healthcare, intelligent transportation management system, agriculture, Brain Computer Interface, retail management, automobile, and many more have led to huge development in cloud computing and its associated technologies. The Amazon Web Service (AWS) has declared that by 2020 , there will be 20.6 billion connected devices across world, and this number will be 1.0 trillion by 2025 . The extreme development has headed to rise in the number of cloud users across the world and increase the load on cloud datacenters, which in turn, has reduced the Quality of Service (QoS). Traditional techniques in the cloud for providing good QoS in scheduling, load balancing, Virtual Machine (VM) consolidation, VM migration, VM placement, resource scheduling and optimization, resource allocation, VM allocation are not able to grip good QoS for cloud users and may reduce number of users for cloud provider.

The era of the 21 st century has come up with many heuristic, meta-heuristic, nature-inspired, bio-inspired techniques to solve problems of cloud computing [1]. Ant colony, optimization (ACO), Particle Swarm Optimization (PSO), Firefly Algorithm Optimization (FA), Ant Lion Optimization (ALO), Genetic Algorithm (GA), Bat inspired Algorithm (BA), Cat Swarm Optimization (CSO), Monkey Search Algorithm (MSO) etc. are some examples of swarm based optimization techniques which are applied in cloud computing and other optimization problems of engineering. Many nature inspired algorithms like Differential Evolution (DE), Japanese Tree Frogs Calling (JTFC), Invasive Weed Optimization (IWO), Flower Pollination Optimization (FPO), Paddy Field Optimization (PFO), etc. are used in solving various problems of cloud computing. In recent years, the hybridization of the various optimization algorithm is used in cloud computing. The application of hybrid techniques appears to be more powerful in the optimization of multi objective parameters of cloud computing. The success rate of nature inspired techniques in a combination of swarm based is more to solve NP hard problems. This article reviews the application of various swarm based, nature inspired based, and hybrid techniques in cloud computing and analyze their effectiveness in solving various issues in cloud computing environment. 


\section{Research Challenges in Cloud Computing}

Nayak et al. [1] discussed various challenges of cloud computing. The article also discusses the use of nature inspired algorithms in cloud computing. Automatic task/workflow scheduling, load balancing, VM migration, energy efficient management, intelligent VM placement, load prediction, QoS, efficient resource scheduling, and management are some of the major challenges in cloud, and many techniques have been developed to solve them.

\subsection{Scheduling}

Scheduling of tasks/jobs is an emerging challenge in the cloud for researchers. The independent tasks or interconnected tasks (workflow) to be executed in a limited number of resource with better QoS is still a big challenge in the cloud.

\subsection{Load Balancing}

Load balancing is a mechanism that deals with equal distribution of load on cloud resources and to keep CPU utilization of all machines at the same level. It also helps to minimize energy in cloud datacenters as underutilized VMs can be switched off or can be put on idle state.

\subsection{VM Migration}

VM migration technique is the migration of VMs from one host to another. In recent years, live VM migration emerges as a sub challenge in the cloud. It helps to minimize the number of virtual machines, energy minimization, and efficient utilization of various resources in the datacenter.

\subsection{Load Prediction}

Workload prediction in cloud computing helps to estimate the future requirement of resources in the cloud. It helps in the efficient management of resources, scheduling, and to keep the system balanced. In recent years, research is carried out to predict the workload by applying various machine learning techniques. However, due to dynamic environment of users, it is very challenging to predict the workload in real time.

\subsection{VM Placement}

VM placement is an NP-Complete problem in a cloud by nature. The main aim of VM placement is to place all VMs in a minimum number of physical hosts. It helps in minimizing the energy, number of VM migration, and resource utilization of hosts. Researchers have proposed many techniques to solve VM placement, but still, it is a challenging research area.

\subsection{Resource Scheduling and Management}

Cloud computing has are infinite number of resources for users in the cloud computing environment. Any user can increase or decrease his/her demands as per their requirements at any instant of time. Resource scheduling and management allow high profit to the cloud provider by increasing their utilization by allocating different resources to users. Many resource scheduling and management algorithms have been proposed in order to get high utilization with minimum expense; still, it is a challenge for academicians, researchers, and scientists.

\section{Computational Intelligence in Cloud Computing}

The applications of optimization algorithms in cloud computing can be categorized into three parts: Swarm Intelligence (SI) algorithms, Nature Inspired algorithms, and hybrid algorithms. These algorithms are applied to find solution of various problems of cloud computing. Fig. 1 shows different percentage contribution of these algorithms in cloud computing. Swarm intelligence based algorithm contributed 31\%, nature inspired contributed $29 \%$, and the hybrid algorithm contributed a maximum of $40 \%$ application in cloud computing. 


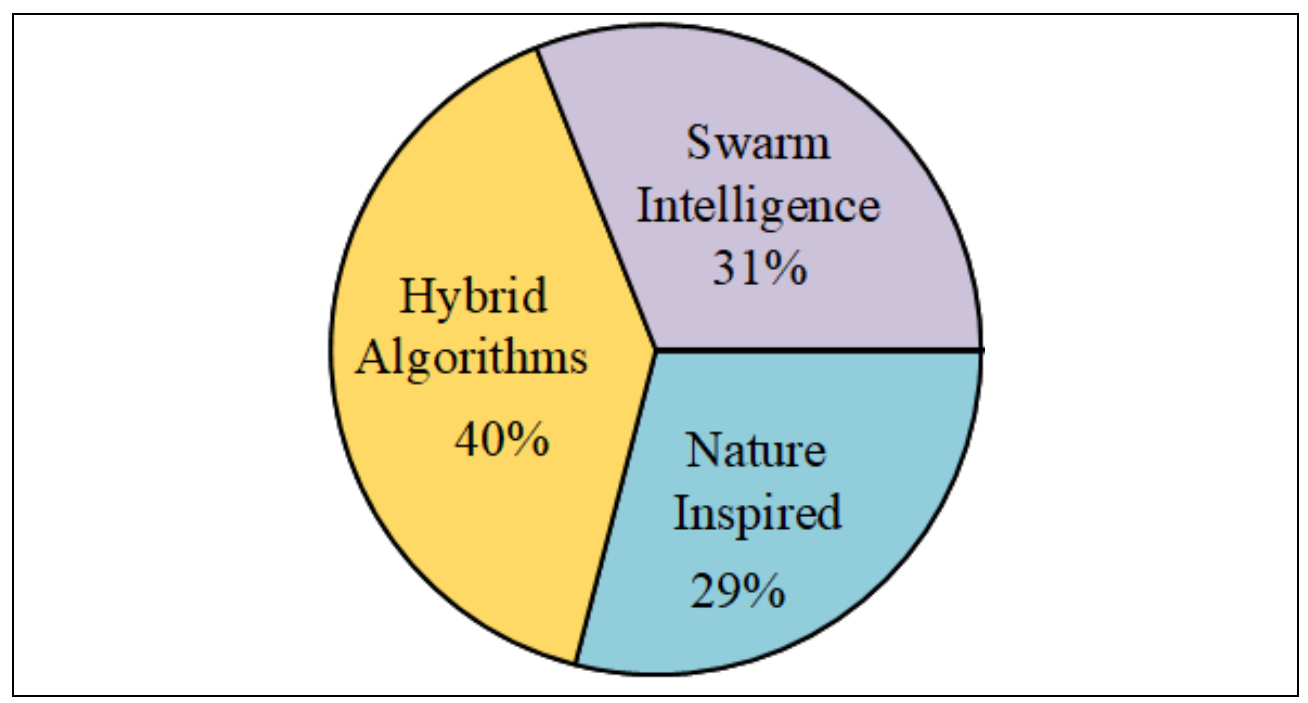

Fig. 1 Contribution of Computational Intelligence based Algorithms in Cloud Computing

\subsection{Swarm intelligence based techniques}

In recent years, swarm intelligence (SI) has gained attention among various researchers, scientists, and academicians. The capability of self-organizing and division of labor are two basic fundamental concepts of SI. The capability of these algorithms to solve many engineering domains is widely used in real life. Some of SI algorithms like ACO, PSO, Salp Swarm Optimization, Grey Wolf, Whale Optimizer, Gravitational Search Optimization, and many more have played a very important role in solving the various problems of cloud computing.

Minoo Soltanshah et al. [2] presented a VM allocation method based on Krill Herd optimization in which krill represents the virtual machines and the baits represent the physical machines in order to minimize Service Level Agreement (SLA) violation, energy consumption, Energy SLA Violation(ESV) in the datacenter. The study finds that energy consumption using the KH optimization algorithm can be reduced by $35 \%$ and $17 \%$ as compared to a GA and MBFD algorithm. Shayem Saleh et al. [3] applied salp swarm optimization with sine cosine to solve VM placement problems with aim to reduce power consumption and minimize SLA violations. The algorithm is implemented in java on the cloud-sim simulator and shows significance improvement when compared with MOCSO, MOPSO, MOEAD, and MOGA. Gang Li et al. in [4] discussed the task scheduling with load imbalance in System Wide Information Management and proposed the ACO based algorithm using hardware performance quality index. The technique is implemented on NS-2 which consists of 100 tasks on 50 nodes. The proposed study shows that it improves the system resources utilization, reduces execution time and maintain the system balance as compared to traditional min-max, ACO, and PSO.

Gobalakrishnan Natesan et al. [5] modified GWO algorithm into multi-objective to reduce makespan and energy in the cloud system. The algorithm is implemented in java using cloud-sim simulation on standard data set (normal and uniform) and achieves good improvement in terms of makespan by $8.85 \%$ and $9.2 \%$ reduction in energy consumption when compared with PSO and standard GWO algorithm. Sreenu et al. [6] presented a multi objective scheduling for the cloud using the Whale Optimization algorithm in order to minimize the cost and makespan. The author initially used an impartial model to calculate the fitness value and then add the cost function of memory and CPU in order to map the tasks to virtual machine optimally. The simulation is done on the cloud-sim with four different task set consists of 100, 200, 300, and 400 tasks and shows significance improvement when compared with ACO and PSO in terms of makespan and cost. Huang et al. [7] developed a task scheduling approach using PSO technique in order to drop the makespan and cost. The PSO algorithm is modified with time varying inertia weight strategy for the fitness function. The algorithm is implemented in Matlab 2013a on five different task sets consist of 30, 50, 100, 200, and 300 tasks and gave an improvement in average makespan when with gravitational search, artificial bee colony, and dragon-fly algorithm. Similarly, Divya Chaudhary et al. [8] discussed a load scheduling algorithm using particle swarm optimization to reduce total transfer time and total cost. It helps the system in a balanced state by making CPU utilization in a balanced manner. The algorithm is implemented in Network cloud sim, and results are compared with FCFS, Min-Max, original PSO and give better performance. 
Jasim Mohammad et al. [9] proposed a technique by combining the greedy algorithm with Ant-lion optimization algorithm (GALO) for scheduling in order to reduce makespan, cost of execution, and execution time. Greedy algorithm increases the local states and ant lion schedule tasks to global ones. The results show that GALO has better efficiency than existing ones. X. Liu et al. [10] designed an energy efficient model based on ACO to place virtual machine in order to minimize the energy. The testbed is designed in $\mathrm{C}++$ and tested in heterogeneous and homogeneous datacenters to evaluate efficiency.

The comparative analysis of swarm based techniques in cloud computing is presented in table 1.

Table 1. Comparative Analysis of Swarm based techniques

\begin{tabular}{|c|c|c|c|c|c|}
\hline Year & $\begin{array}{c}\text { Optimization } \\
\text { Technique Applied }\end{array}$ & $\begin{array}{l}\text { Parameter } \\
\text { Optimized }\end{array}$ & Environment & Problem & Reference \\
\hline 2019 & Krill Herd algorithm & Energy Consumption & CloudSim & $\begin{array}{l}\text { Virtual Machine } \\
\text { Allocation }\end{array}$ & {$[2]$} \\
\hline 2019 & $\begin{array}{l}\text { Salp Swarm } \\
\text { optimization }\end{array}$ & $\begin{array}{l}\text { Energy and SLA } \\
\text { violation }\end{array}$ & CloudSim & $\begin{array}{l}\text { Virtual machine } \\
\text { Placement }\end{array}$ & [3] \\
\hline 2019 & $\begin{array}{l}\text { ant colony optimization } \\
\text { (ACO) }\end{array}$ & $\begin{array}{l}\text { Makespan and } \\
\text { resource utilization }\end{array}$ & $\begin{array}{c}\text { Network } \\
\text { simulator-3 }\end{array}$ & Load balancing & {$[4]$} \\
\hline 2019 & $\begin{array}{c}\text { Mean Grey Wolf } \\
\text { Optimization algorithm }\end{array}$ & $\begin{array}{c}\text { Makespan and } \\
\text { energy consumption }\end{array}$ & CloudSim & Task scheduling & {$[5]$} \\
\hline 2019 & Whale optimization & Makespan and cost & CloudSim & Task scheduling & {$[6]$} \\
\hline 2019 & $\begin{array}{l}\text { particle swarm } \\
\text { optimization }\end{array}$ & Makespan & Matlab & Task scheduling & {$[7]$} \\
\hline 2018 & $\begin{array}{c}\text { Particle Swarm } \\
\text { Optimization }\end{array}$ & $\begin{array}{l}\text { total transfer time } \\
\text { and total cost }\end{array}$ & $\begin{array}{l}\text { Network } \\
\text { CloudSim }\end{array}$ & Task scheduling & {$[8]$} \\
\hline 2018 & $\begin{array}{l}\text { Ant-lion Optimizer } \\
\text { algorithm }\end{array}$ & $\begin{array}{l}\text { Makespan, total cost } \\
\text { and execution time. }\end{array}$ & Not Mention & Task scheduling & [9] \\
\hline 2018 & $\begin{array}{l}\text { Ant Colony } \\
\text { Optimization }\end{array}$ & $\begin{array}{l}\text { Energy, CPU and } \\
\text { RAM Utilization }\end{array}$ & $\begin{array}{l}\mathrm{C}++ \text { based } \\
\text { simulator }\end{array}$ & $\begin{array}{l}\text { Virtual Machine } \\
\text { Placement }\end{array}$ & {$[10]$} \\
\hline
\end{tabular}

\subsection{Nature Inspired Techniques}

Nature inspired algorithms are capable of solving NP-Hard problems. These algorithms do not trap at a local or global position and have a good response in terms of convergence rate. The capability of solving many real life problems by hit and trail method focuses researchers on developing some competitive optimization problems. Various problems of cloud computing have been solved by nature inspired algorithms.

S. Elsherbiny et al. [11] proposed an extended water drops algorithm to schedule the scientific workflow in cloud taking cost and makespan as parameters. They divides the algorithm into three phase; initializing phase, path constructing phase, and task assignment to the virtual machine. The algorithm is implemented in workflowsim simulator which is specially designed for a workflow like Sipht, Cybershake etc. The study is compared to Min-Max, Max-Min, FCFS, Round Robin and MCT algorithm and finds that it outperforms taking cost and makespan as parameters of Quality of Service [11]. Mohammed et al. [12] applied flower pollination algorithm to assign resources in the cloud by aiming to minimize the energy consumed in datacentres. The algorithm is implemented in Multi-Rec cloud-sim on the planet-lab data set having 125 hosts, $285 \mathrm{VMs}$, with 25 users. The algorithm is compared with GA and original FPA in terms of CPU utilization and energy and saves an average of $35 \%$ energy in datacentres.

Mandeep et al. [13] modified bacteria foraging optimization algorithm to schedule independent jobs on virtual machines. The original algorithm is modified with Pare-to optimal front approach to handle multi objective scheduling. It shows significant improvement in terms of cost, flow time, and resource usage in comparison with GA and PSO. Abdel et al. [14] improved the WOA algorithm with a levy to place the VMs on the host to maximize CPU utilization. The algorithm was examined on 50 different data sets generated and compare with the best fit, first fit, PSO, GA, and harmony search. The analysis was carried out using the Friedman test to check the validity and convergence of the proposed algorithm. Divya Chaudhary et al. [15] applied GSA technique to minimize the transfer time and total cost in cloud computing. The cloudy GSA is implemented in Network cloud-sim and results signify the near optimal results as compared to Min-Max, SA, GA, Tabu Search, PSO, and FCFS. Kudamaduwage et al. [16] presented a resource allocation algorithm using virus colony search technique for energy consumption. The author has simulated the proposed algorithm taking virtual machines ranging from 25 to 200 and workload from the CoMon data project and resolve the problem of 
stuck in local point. The proposed shows algorithm significant improvement over NSGAII and MOEAD in terms of SLA violations, energy, and the number of VM migrations. Table 2 summarizes and analyses natureinspired algorithms in cloud computing.

Table 2. Comparative Analysis of Nature Inspired Techniques

\begin{tabular}{|c|c|c|c|c|c|}
\hline Year & $\begin{array}{c}\text { Optimization Technique } \\
\text { Applied }\end{array}$ & Parameter Optimized & Environment & Problem & Reference \\
\hline 2019 & $\begin{array}{l}\text { Water cycle optimization } \\
\text { wavelet neural network } \\
\text { algorithm }\end{array}$ & $\begin{array}{l}\text { Reduces error rate and } \\
\text { improves Mean Absolute } \\
\text { Percentage error }\end{array}$ & Matlab & $\begin{array}{l}\text { Workload } \\
\text { prediction }\end{array}$ & [17] \\
\hline 2019 & $\begin{array}{l}\text { Flower Pollination } \\
\text { Algorithm }\end{array}$ & $\begin{array}{l}\text { Energy consumption, } \\
\text { resource utilization, }\end{array}$ & $\begin{array}{l}\text { Multi-Rec- } \\
\text { CloudSim }\end{array}$ & $\begin{array}{l}\text { Virtual machine } \\
\text { allocation }\end{array}$ & {$[12]$} \\
\hline 2018 & $\begin{array}{c}\text { Extended Intelligent } \\
\text { Water Drops algorithm }\end{array}$ & $\begin{array}{l}\text { Makespan and cost of } \\
\text { execution }\end{array}$ & CloudSim & $\begin{array}{l}\text { Workflow } \\
\text { scheduling }\end{array}$ & [11] \\
\hline 2018 & $\begin{array}{c}\text { Bacteria foraging } \\
\text { optimization algorithm }\end{array}$ & $\begin{array}{l}\text { Flow time, makespan, } \\
\text { resource cost, }\end{array}$ & CloudSim & $\begin{array}{c}\text { Task } \\
\text { Scheduling }\end{array}$ & [13] \\
\hline 2018 & $\begin{array}{l}\text { Lévy based whale } \\
\text { optimization }\end{array}$ & Datacentre Utilization & CloudSim & $\begin{array}{l}\text { Virtual Machine } \\
\text { Placement }\end{array}$ & [14] \\
\hline 2018 & $\begin{array}{c}\text { Gravitational Search } \\
\text { optimization Algorithm }\end{array}$ & transfer time total cost & CloudSim & $\begin{array}{c}\text { Task } \\
\text { Scheduling }\end{array}$ & {$[15]$} \\
\hline 2018 & $\begin{array}{l}\text { Virus Colony Search } \\
\text { Optimization }\end{array}$ & $\begin{array}{l}\text { Energy, SLA Violation, and } \\
\text { number of Virtual Machine } \\
\text { Migration (VMM). }\end{array}$ & CloudSim & $\begin{array}{l}\text { Resource } \\
\text { Allocation }\end{array}$ & {$[16]$} \\
\hline 2018 & $\begin{array}{l}\text { Flower Pollination } \\
\text { Algorithm }\end{array}$ & $\begin{array}{l}\text { Energy and resource } \\
\text { Utilization }\end{array}$ & $\begin{array}{l}\text { Multi-Rec- } \\
\text { CloudSim }\end{array}$ & $\begin{array}{l}\text { Resource } \\
\text { Allocation }\end{array}$ & [18] \\
\hline
\end{tabular}

\subsection{Hybrid Optimization Algorithms}

In recent years, hybrid techniques evolve in every domain of engineering, medical, and management to find a pare-to optimal solution. Many researchers have applied a combination of swarm based on nature inspired to find an optimal solution in various problems of cloud computing. The hybrid optimization techniques find a pare-to optimal solution in load balancing, scheduling, energy management, etc. These techniques are able to optimize more than one parameter and can find a solution where one parameter cannot dominate the other.

M. Elaziz et al. [19] merged moth search algorithm and differential evolution (MSDE) for mapping of tasks/cloudlets to different virtual machines in the cloud environment. The algorithm works in two phases to minimize makespan as compared to heuristic and meta- heuristic techniques; in the first phase, a random number $\mathrm{N}$ is created with size $\mathrm{S}$ with dimension equal to the quantity of tasks. The second phase uses differential equation to improve the exploitation ability of Moth Search. Aravind et al. [20] presented an optimal hybrid technique based on firefly and genetic algorithm which forms a powerful metaheuristic search technique to decrease the execution time. The author compares the execution time of this algorithm with FIFO and genetic algorithm, however, comparison with more heuristic techniques will give more performance improvement. C. Jatoth et al. [21] gave modified invasive weed optimization for optimal fitness aware cloud services to boost the Quality of Service. Data sets of real world cloud services were applied to examine the enactment of proposed technique.

Syed Hamid et al. [22] applied cuckoo search to schedule the tasks/cloudlets to the virtual machines in order to minimize the cost and makespan. He extends the basic cuckoo search algorithm to bind independent tasks/cloudlets to virtual machines as one nest may have more than one egg. The proposed algorithm is implemented on cloud-sim using three different standard workload file, namely; HPC2N, NASA, and SDSC. The algorithm is compared with MOACO, MOGA, MOPSO, MOCSO and MOMM. Similarly, the author [23] presented a hybrid technique for scheduling in cloud by combing the Gradient Descent and Cuckoo Search optimization technique. The local search is optimized by Gradient Descent and global search is done using cuckoo search. The author used three different workloads namely; HPC2N, NASA, and SDSC to evaluate the performance improvement rate, makespan, throughput, degree of balance using cloud sim in java. The algorithm is compared with original Cuckoo, ACO, GA, ABC, LCA, SA, and PSO. Pradeep et al. [24] developed a hybrid task scheduling algorithm by combining the features of Cuckoo search and Harmony search optimization. Cuckoo search is used for local search in population while a global search is done by the harmony search. The 
combination of two algorithms is used to schedule the tasks more efficiently in terms of cost, energy, penalty, profit, memory utilization.

Kesavaraja et al. [25] designed a technique to allocate VM using the eagle strategy of krill herd optimization. The algorithm has two parts; response protocol, and agreement protocol, to forecast the optimal resources for the virtual machine to escape the eccentrics and clogging. The experiment is carried out in a testbed consists of Private Cloud Open Stack with Amazon EC2, having 82 physical nodes. This technique provides a good Quality of Experience (QoE) in terms of delay, latency, packet rate, and throughput when compared with ACO, GA, and SA. Jethava et al. [26] proposed task scheduling algorithm technique by combining $\mathrm{ACO}$ and Black Hole optimization algorithm for workflow scheduling to minimize the task compilation time, efficient utilization of resources, and makespan. The proposed algorithm is implemented on the workflow simulator which is built on the top of cloud-sim. Fathima et al. [27] projected a fusion algorithm using Firefly and GA to schedule tasks to virtual machines in order to minimize execution time. The algorithm works in two phases. The mapping of tasks to virtual machines is done by firefly and the results of firefly are used as base population for genetic algorithm to optimize the results. The algorithm is implemented in cloudsim and iterations were increased in factor of 10 to evaluate the results.

Karthikeyan et al. [28] introduced virtual machine migration algorithm using the Naive Bayes classifier with artificial bee colony and bat algorithm to reduce the energy consumption in cloud datacenters. The concert of the algorithm is evaluated in cloud-sim in terms of success rate and failure rate. The author has used machine learning to predict the success and failure of virtual machine migration. Gomathi et al. [29] proposed a multi objective task scheduling problem for cloud computing by the combination of epsilon fuzzy and artificial bee colony optimization. The continuous $\mathrm{ABC}$ algorithm is modified as composite discrete with Epsilon fuzzy dominance to generate Pareto optimal solution in a multi objective function. The implementation is done on cloud sim using HPC2N workload on three datacenters having 5 physical hosts. Each host has 5 virtual machines. The algorithm succeeds better than NSGAII and MOPSO in terms of makespan, execution cost and CPU utilization. Gabi et al. [30] projected an orthogonal Taguchi-based cat algorithm to schedule tasks on virtual machines in the cloud environment to minimize the task execution delay. The degree of imbalance was evaluated to distribute the tasks on virtual machines equally. The experiments were performed in cloud-sim with three different scenarios having 5,10 and 20 numbers of virtual machines and minimize makespan as compared to Min-max, PSO, hybrid PSO with simulated annealing. Gobalakrishnan et al. [31] designed a technique by combining the features of genetic algorithm and Gray Wolf Optimization (GWO) with an aim to minimize the cost of execution, energy, migration cost and to increase the fitness function. The performance of the algorithm is evaluated by applying the scientific workflows on workflow-sim. Ahmad et al. [32] proposed a hybrid algorithm by combining the features of GA and PSO for scheduling of workflow in cloud computing to reduce the cost of execution, makespan and to balance the system. The population generated by GA is used by PSO to update the velocity and position and to calculate the best solution. WorkflowSim signifies the results of Hybrid GA-PSO algorithm over GA, PSO. A summary of hybrid algorithms in cloud computing is presented in table 3.

Table 3. Comparative Analysis of Hybrid Techniques

\begin{tabular}{|c|c|c|c|c|c|}
\hline Year & $\begin{array}{c}\text { Optimization Technique } \\
\text { Combination }\end{array}$ & Parameter Optimized & Environment & Problem & Reference \\
\hline 2021 & Hybrid GA-PSO & $\begin{array}{l}\text { Delay, resource utilization, } \\
\text { energy, }\end{array}$ & Fogsim & $\begin{array}{l}\text { Resource } \\
\text { Alloaction }\end{array}$ & [33] \\
\hline 2020 & $\begin{array}{l}\text { Hybrid Firefly-Genetic } \\
\text { Algorithm }\end{array}$ & Makespan & CloudSim & $\begin{array}{c}\text { Task } \\
\text { Scheduling }\end{array}$ & [20] \\
\hline 2019 & $\begin{array}{l}\text { ACO with Black Hole } \\
\text { Algorithm }\end{array}$ & $\begin{array}{l}\text { Makespan and total } \\
\text { execution cost }\end{array}$ & CloudSim & $\begin{array}{c}\text { Task } \\
\text { Scheduling }\end{array}$ & [26] \\
\hline 2019 & $\begin{array}{c}\text { Eagle Strategy with } \\
\text { Whale Optimization } \\
\text { Algorithm }\end{array}$ & $\begin{array}{l}\text { Optimal QoS values for the } \\
\text { requirement of user }\end{array}$ & Matlab & $\begin{array}{l}\text { Cloud service } \\
\text { composition }\end{array}$ & [21] \\
\hline 2019 & $\begin{array}{l}\text { Hybrid gradient descent } \\
\text { cuckoo search (HGDCS) } \\
\text { algorithm }\end{array}$ & $\begin{array}{l}\text { Makespan, throughput, and } \\
\text { load balancing }\end{array}$ & CloudSim & $\begin{array}{l}\text { Resource } \\
\text { scheduling }\end{array}$ & [23] \\
\hline 2019 & $\begin{array}{l}\text { Hybrid moth search and } \\
\text { DE }\end{array}$ & Makespan & CloudSim & Task scheduling & [19] \\
\hline 2018 & $\begin{array}{l}\text { Hybrid Eagle strategy and } \\
\text { krill herd optimization }\end{array}$ & $\begin{array}{l}\text { Server Utilization, revenue, } \\
\text { energy, SLA violation }\end{array}$ & $\begin{array}{l}\text { Cloud Open } \\
\text { stack and }\end{array}$ & $\begin{array}{l}\text { Virtual machine } \\
\text { allocation }\end{array}$ & {$[25]$} \\
\hline
\end{tabular}




\begin{tabular}{|c|c|c|c|c|c|}
\hline 2018 & $\begin{array}{c}\text { Particle Swarm } \\
\text { Optimization and } \\
\text { Gravitational Search } \\
\text { Algorithm }\end{array}$ & $\begin{array}{c}\text { Average VM load Average } \\
\text { VM processing speed }\end{array}$ & CloudSim & $\begin{array}{c}\text { Task } \\
\text { Scheduling and } \\
\text { load balancing }\end{array}$ & {$[15]$} \\
\hline 2018 & GA and PSO Algorithm & $\begin{array}{c}\text { Makespan, execution cost, } \\
\text { load balance rate }\end{array}$ & WorkflowSim & $\begin{array}{c}\text { Workflow } \\
\text { Scheduling }\end{array}$ & {$[32]$} \\
\hline 2018 & $\begin{array}{c}\text { Artificial Bee Colony-Bat } \\
\text { Algorithm }\end{array}$ & $\begin{array}{c}\text { Performance Index in } \\
\text { success \&failure rate } \\
\text { Energy }\end{array}$ & CloudSim & $\begin{array}{c}\text { Virtual Machine } \\
\text { Migration }\end{array}$ & {$[28]$} \\
\hline 2018 & $\begin{array}{c}\text { Cuckoo and Harmony } \\
\text { Search }\end{array}$ & $\begin{array}{c}\text { Cost, energy, memory, } \\
\text { credit and penalty. }\end{array}$ & CloudSim & $\begin{array}{c}\text { Task } \\
\text { Scheduling }\end{array}$ & {$[24]$} \\
\hline 2018 & $\begin{array}{c}\text { Genetic Gray Wolf } \\
\text { Optimization } \\
\text { Computation time, } \\
\text { migration cost, energy and } \\
\text { load utilization }\end{array}$ & CloudSim & {$[31]$} \\
\hline 2018 & $\begin{array}{c}\text { Orthogonal Taguchi-based } \\
\text { COA }\end{array}$ & $\begin{array}{c}\text { Makespan, Degree of } \\
\text { imbalance, }\end{array}$ & CloudSim & $\begin{array}{c}\text { Task } \\
\text { Scheduling }\end{array}$ & {$[30]$} \\
\hline Epsilon-fuzzy with & $\begin{array}{c}\text { Makespan, cost and } \\
\text { resource utilization }\end{array}$ & CloudSim & Task scheduling & {$[29]$} \\
\hline
\end{tabular}

\section{Analysis and Discussion}

In this section, an analysis of various optimization algorithms in cloud computing is done. The application of various swarm intelligence, nature inspired algorithms, and hybrid algorithms are gradually increased in recent years. As stated above that $31 \%$ of algorithms applied to solve various research problems falls under category of swarm based in cloud computing. Among swarm based algorithms, $56 \%$ algorithms are used to solve scheduling, 22\% algorithms are applied for VM placement. VM allocation and load balancing share equally $11 \%$ of swarm algorithms.

The nature inspired algorithms contribute around $29 \%$ in cloud computing. The scheduling and VM allocation issues have their share of $38 \%$. VM placement and workload prediction share their weightage of $12 \%$ among various nature inspired algorithms. The reason for the application of nature inspired algorithm in scheduling and VM allocation is that these algorithms are capable of handling nonlinearity, and produce good results at global optima. The problem of scheduling and VM allocation have high weightage in providing good QoS in terms of makespan, minimizing execution cost, high resource utilization and are energy efficient.

In the last two years, the hybrid techniques developed by researchers and their application in cloud computing is improved. The combination of any technique either from swarm intelligence or from nature inspired improves the performance of the algorithm and produce good results. Fig. 1 shows that around $40 \%$ of the contribution is hybrid algorithms. The hybrid algorithms are mostly applied to solve the problem of scheduling in the cloud and having a share of $84 \%$. The rest share is equally distributed among VM migration and VM allocation. From the above discussion, it is analyzed that scheduling problem is widely solved by researchers by applying swarm intelligence, nature inspired and their hybrid algorithms.

The fig. 2 shows that $63 \%$ of all three typed techniques are used in the scheduling problem, and it is still a challenging issue for researchers. It can be analysed from fig. 2 that the optimization algorithms are least applied in VM migration. Only $3 \%$ of algorithms are for in VM migration in the cloud. $11 \%$ of techniques are for VM placement, $9 \%$ are for resource allocation, $8 \%$ for VM allocation, and $6 \%$ for load balancing.

Fig. 4 presents the division of techniques in the cloud on the basis of objectives. The bar chart shows that 42 $\%$ of the algorithms are applied to optimize a single parameter; however, in addition to that researchers have evaluated additional parameters like optimizing cost with makespan, energy with utilization. In recent years, multi objective optimization rise in various problems of cloud computing and researchers tried to find a solution where one parameter cannot dominate the solution of another parameter. The pie chart shows us that around $58 \%$ of total techniques are multi objective in nature. This gives the new challenge to researchers to explore more optimized solutions in various problems of cloud computing. 
Fig. 3 shows the use of various simulation environments that were used by researchers, scientists, and academicians in cloud computing. It is clearly visible that cloud sim is the most popular among the researchers. The credit goes to its extensibility, modelling and simulation of energy aware computational resources. The cloud sim allows adding workload dynamically while executing other tasks. It allows users to add their own policies for cloudlet scheduling, VM allocation, scheduling, etc. The Simulink in Matlab is also used for scheduling of jobs, but due to its commercial licence, it is used by $9 \%$ users. The Rec-Cloud-sim, built on the top of cloud sim, is also used in carrying out a simulation of various algorithms of the cloud. The rest simulation tools like network cloud sim, NS-2, workflow sim, open stack are used less for research in cloud computing.

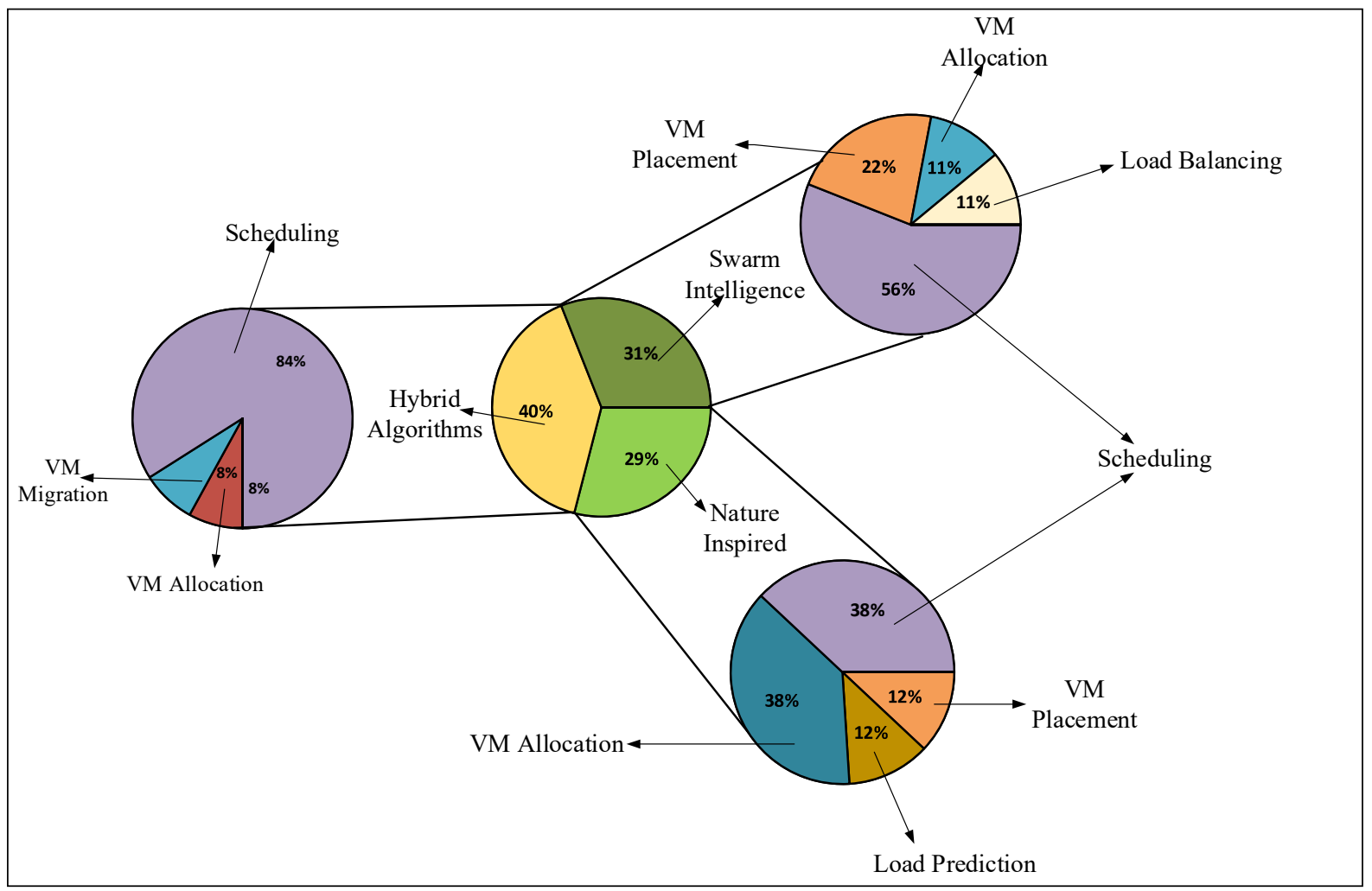

Fig. 2. Contribution of Computational Intelligence Algorithm in Cloud Computing

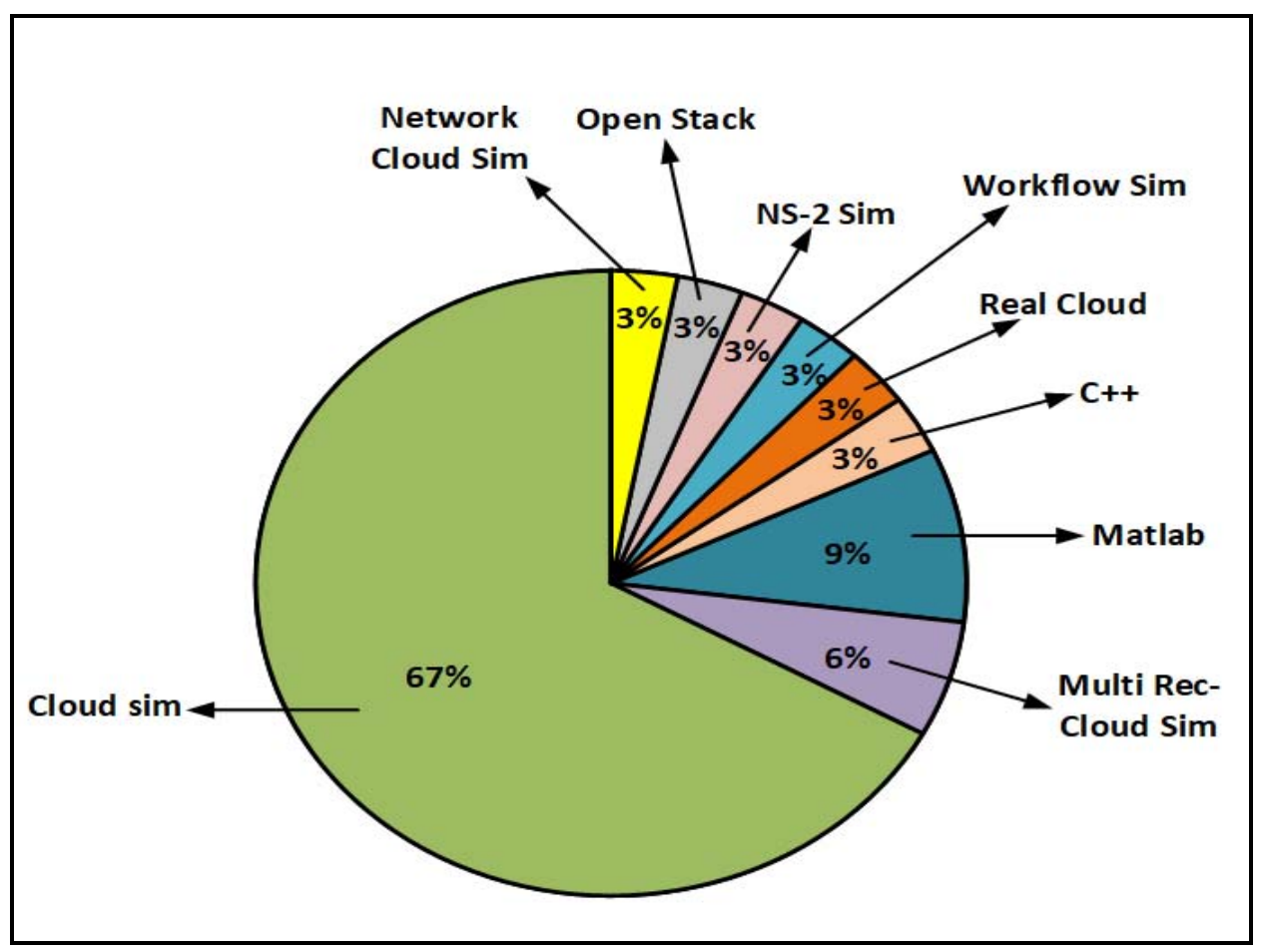

Fig. 3. Contribution of various tools in Cloud Simulation 


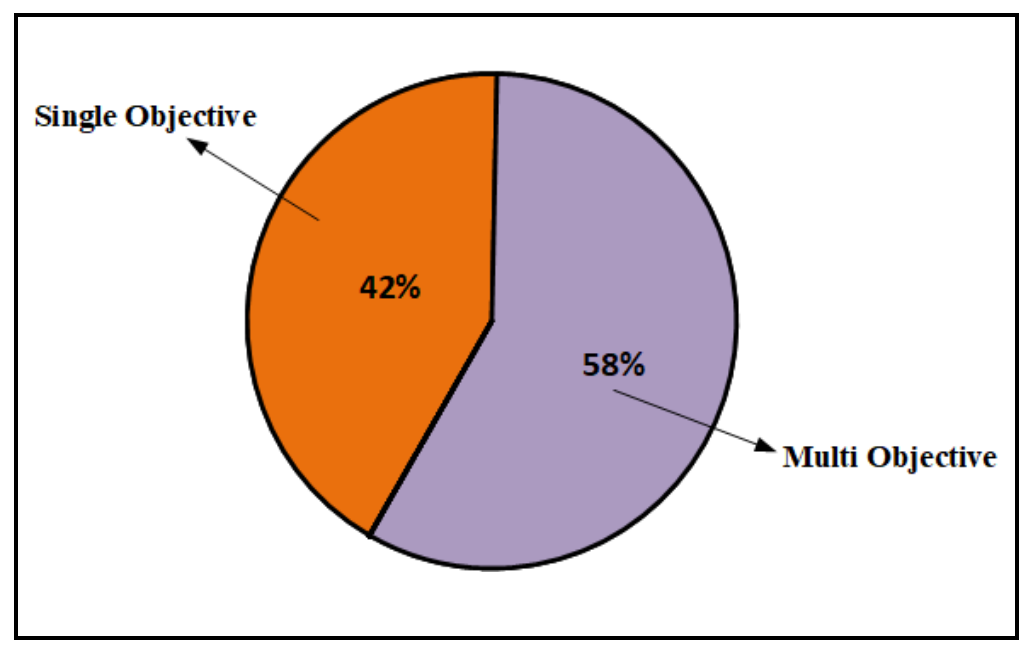

Fig. 4. Objective based contribution

Table 4. Analysis of various parameters in Cloud Computing

\begin{tabular}{|c|c|c|c|c|c|c|c|}
\hline Year & Optimization Technique & Makespan & Energy & Cost & $\begin{array}{l}\text { Resource } \\
\text { Utilization }\end{array}$ & $\begin{array}{c}\text { SLA } \\
\text { Violation }\end{array}$ & $\begin{array}{l}\text { Load } \\
\text { Balance }\end{array}$ \\
\hline 2019 & Krill Herd algorithm & $x$ & $\checkmark$ & $x$ & $x$ & $x$ & $x$ \\
\hline 2019 & Salp Swarm optimization & $x$ & $\checkmark$ & $x$ & $x$ & $\checkmark$ & $x$ \\
\hline 2019 & Ant Colony Optimization (ACO) & $\checkmark$ & $x$ & $x$ & $\checkmark$ & $x$ & $x$ \\
\hline 2019 & $\begin{array}{l}\text { Mean Grey Wolf Optimization } \\
\text { algorithm }\end{array}$ & $\checkmark$ & $\checkmark$ & $x$ & $x$ & $x$ & $x$ \\
\hline 2019 & Whale optimization & $\checkmark$ & $x$ & $v$ & $x$ & $x$ & $x$ \\
\hline 2019 & Particle Swarm optimization & $\checkmark$ & $x$ & $x$ & $x$ & $x$ & $x$ \\
\hline 2018 & Particle Swarm Optimization & $\checkmark$ & $x$ & $\checkmark$ & $x$ & $x$ & $x$ \\
\hline 2018 & Ant-lion Optimizer algorithm & $\checkmark$ & $x$ & $\checkmark$ & $x$ & $x$ & $x$ \\
\hline 2018 & Ant Colony Optimization & $x$ & $\checkmark$ & $x$ & $\checkmark$ & $x$ & $x$ \\
\hline 2019 & $\begin{array}{l}\text { Water Cycle optimization wavelet } \\
\text { neural network algorithm }\end{array}$ & $x$ & $x$ & $x$ & $x$ & $x$ & $x$ \\
\hline 2019 & Flower Pollination Algorithm & $x$ & $\checkmark$ & $x$ & $\checkmark$ & $x$ & $x$ \\
\hline 2018 & $\begin{array}{l}\text { Extended Intelligent Water Drops } \\
\text { algorithm }\end{array}$ & $\checkmark$ & $x$ & $\checkmark$ & $x$ & $x$ & $x$ \\
\hline 2018 & $\begin{array}{l}\text { multi-objective bacteria foraging } \\
\text { optimization algorithm }\end{array}$ & $\checkmark$ & $x$ & $\checkmark$ & $x$ & $x$ & $x$ \\
\hline 2018 & Lévy based whale optimization & $x$ & $x$ & $x$ & $\checkmark$ & $x$ & $x$ \\
\hline 2018 & $\begin{array}{c}\text { Gravitational Search optimization } \\
\text { Algorithm }\end{array}$ & $\checkmark$ & $x$ & $\checkmark$ & $x$ & $x$ & $x$ \\
\hline 2018 & $\begin{array}{l}\text { Virus Colony Search } \\
\text { Optimization }\end{array}$ & $x$ & $\checkmark$ & $x$ & $x$ & $\checkmark$ & $x$ \\
\hline 2018 & Flower Pollination Algorithm & $x$ & $\checkmark$ & $x$ & $\checkmark$ & $x$ & $x$ \\
\hline 2020 & Hybrid Firefly-Genetic Algorithm & $\checkmark$ & $x$ & $x$ & $x$ & $x$ & $x$ \\
\hline
\end{tabular}




\begin{tabular}{|c|c|c|c|c|c|c|c|}
\hline 2019 & ACO and Black Hole Algorithm & $\checkmark$ & $x$ & $\checkmark$ & $x$ & $x$ & $x$ \\
\hline 2019 & $\begin{array}{l}\text { Hybrid gradient descent cuckoo } \\
\text { search (HGDCS) algorithm }\end{array}$ & $\checkmark$ & $x$ & $x$ & $x$ & $x$ & $\checkmark$ \\
\hline 2019 & $\begin{array}{l}\text { hybrid moth search algorithm and } \\
\text { differential evolution }\end{array}$ & $\checkmark$ & $x$ & $x$ & $x$ & $x$ & $x$ \\
\hline 2018 & $\begin{array}{l}\text { Eagle strategy of hybrid krill herd } \\
\text { optimization }\end{array}$ & $x$ & $\checkmark$ & $x$ & $\checkmark$ & $\checkmark$ & $x$ \\
\hline 2018 & $\begin{array}{l}\text { Particle Swarm Optimization and } \\
\text { Gravitational Search Algorithm }\end{array}$ & $\checkmark$ & $x$ & $x$ & $x$ & $x$ & $\checkmark$ \\
\hline 2018 & GA and PSO Algorithm & $\checkmark$ & $x$ & $\checkmark$ & $x$ & $x$ & $\checkmark$ \\
\hline 2018 & $\begin{array}{l}\text { Artificial Bee Colony-Bat } \\
\text { Algorithm }\end{array}$ & $x$ & $\checkmark$ & & $x$ & $x$ & $x$ \\
\hline 2018 & Cuckoo and Harmony Search & $\checkmark$ & $\checkmark$ & $\checkmark$ & $x$ & $\checkmark$ & $x$ \\
\hline 2018 & Genetic Gray Wolf Optimization & $\checkmark$ & $\checkmark$ & $\checkmark$ & $\checkmark$ & $x$ & $x$ \\
\hline 2018 & $\begin{array}{c}\text { Orthogonal Taguchi-based cat } \\
\text { Optimization }\end{array}$ & $\checkmark$ & $x$ & $x$ & $x$ & $x$ & $\checkmark$ \\
\hline 2018 & $\begin{array}{l}\text { Epsilon-fuzzy dominance sort- } \\
\text { based composite discrete artificial } \\
\text { bee colony optimization }\end{array}$ & $\checkmark$ & $x$ & $\checkmark$ & $\checkmark$ & $x$ & $x$ \\
\hline
\end{tabular}

\section{Conclusion and Future Scope}

Nature inspired optimization has played a vital role in cloud computing. The capabilities of swarm based algorithms can be enhanced by combining them with nature inspired algorithms. The hybrid techniques are more powerful with high convergence rate and they did not get trapped in local optima. In this article, a state of the art of these algorithms is studied and presented their analysis. Hybrid algorithms are gaining more and more attention to solve various problems in cloud computing are presented and analyzed. These algorithms are now applied to get multi objective solutions in scheduling and VM placement. Trade -off between the cost of execution and makespan is minimized by researchers and tried to find optimal solution. It is very much clear from analysis that the majority of scheduling algorithms are applied to optimize cost, execution time, waiting time and flow time.

Many issues of cloud computing are not still explored by scientists like efficient resource utilization is still a big challenge. The multi objective optimization with one parameter cannot dominate another is still an issue and can be explored. Various machine learning and deep learning techniques can be applied to predict load for a dynamic environment in homogeneous and heterogeneous datacentres. Security and privacy are always an important deal in every phenomenon and so with the cloud. Penalty cost while violating SLA is still unexplored, and there is no proper method to calculate it for both users and providers. Many new optimization techniques based on chemical reactions, weather based optimization, multi verse optimization, elephant herding optimization, social spider optimization, kidney inspired, intrusive tumor growth optimization etc. are yet to be applied in future. The deep learning and machine learning techniques can also boost cloud computing by estimating the load prediction and performing VM scaling in the datacenter at peak time. Quantum computing will also knock cloud by increasing the speed and quality of service to users. This article presents a state-of-art scheduling technique used in cloud computing and presents the various challenges in scheduling. Finally, we present the future of scheduling in the cloud with hybridization techniques.

\section{Acknowledgement}

This research work is supported by University Grant Commission under National Fellowship Programme, under Ministry of Social Justice and Empowerment, Govt. of India, grant no. 2017-18/29146. Author also acknowledges Department of Computer Science and Engineering, Deenbandhu Chhotu Ram University of Science and Technology, Murthal, Sonepat for providing various facilities in research lab. 


\section{References}

[1] J. Nayak, B. Naik, A. K. Jena, R. K. Barik, and H. Das, "Nature Inspired Optimizations in Cloud Computing: Applications and Challenges," 2018, pp. 1-26.

[2] M. Soltanshahi, R. Asemi, and N. Shafiei, "Energy-aware virtual machines allocation by krill herd algorithm in cloud data centers," Heliyon, vol. 5, no. 7, pp. 3-8, 2019.

[3] S. S. Alresheedi, S. Lu, M. Abd Elaziz, and A. A. Ewees, "Improved multiobjective salp swarm optimization for virtual machine placement in cloud computing," Human-centric Comput. Inf. Sci., vol. 9, no. 1, pp. 1-24, 2019.

[4] G. Li and Z. Wu, "Ant colony optimization task scheduling algorithm for SWIM based on load balancing," Futur. Internet, vol. 11, no. 4, pp. 1-18, 2019.

[5] G. Natesan and A. Chokkalingam, "Optimal task scheduling in the cloud environment using a mean Grey Wolf Optimization algorithm,” Int. J. Technol., vol. 10, no. 1, pp. 126-136, 2019.

[6] K. Sreenu and M. Sreelatha, "W-Scheduler: whale optimization for task scheduling in cloud computing," Cluster Comput., vol. 22, no. s1, pp. 1087-1098, 2019.

[7] X. Huang, C. Li, H. Chen, and D. An, "Task scheduling in cloud computing using particle swarm optimization with time varying inertia weight strategies," Cluster Comput., vol. 5, pp. 1-11, 2019.

[8] D. Chaudhary and B. Kumar, "A New Balanced Particle Swarm Optimisation for Load Scheduling in Cloud Computing," J. Inf. Knowl. Manag., vol. 17, no. 1, 2018.

[9] O. K. J. Mohammad, "GALO: A new intelligent task scheduling algorithm in cloud computing environment,” Int. J. Eng. Technol., vol. 7, no. 4, pp. 2088-2094, 2018.

[10] X. F. Liu, Z. H. Zhan, J. D. Deng, Y. Li, T. Gu, and J. Zhang, "An Energy Efficient Ant Colony System for Virtual Machine Placement in Cloud Computing," IEEE Trans. Evol. Comput., vol. 22, no. 1, pp. 113-128, 2018.

[11] S. Elsherbiny, E. Eldaydamony, M. Alrahmawy, and A. E. Reyad, "An extended Intelligent Water Drops algorithm for workflow scheduling in cloud computing environment," Egypt. Informatics J., vol. 19, no. 1, pp. 33-55, 2018.

[12] M. J. Usman et al., "Energy-efficient Virtual Machine Allocation Technique Using Flower Pollination Algorithm in Cloud Datacenter: A Panacea to Green Computing," J. Bionic Eng., vol. 16, no. 2, pp. 354-366, 2019.

[13] M. Kaur and S. Kadam, "A novel multi-objective bacteria foraging optimization algorithm (MOBFOA) for multi-objective scheduling,” Appl. Soft Comput. J., vol. 66, pp. 183-195, 2018.

[14] M. Abdel-Basset, L. Abdle-Fatah, and A. K. Sangaiah, "An improved Lévy based whale optimization algorithm for bandwidthefficient virtual machine placement in cloud computing environment," Cluster Comput., vol. 22, pp. 8319-8334, 2019.

[15] D. Chaudhary and B. Kumar, "Cloudy GSA for load scheduling in cloud computing," Appl. Soft Comput. J., vol. 71, pp. 861-871, 2018.

[16] K. P. N. Jayasena, L. Li, M. Abd Elaziz, and S. Xiong, "Multi-objective Energy Efficient Resource Allocation Using Virus Colony Search (VCS) Algorithm," in Proceedings - 20th International Conference on High Performance Computing and Communications, 16th International Conference on Smart City and 4th International Conference on Data Science and Systems, HPCC/SmartCity/DSS 2018, 2019, pp. 766-773.

[17] S. Jeddi and S. Sharifian, "A water cycle optimized wavelet neural network algorithm for demand prediction in cloud computing," Cluster Comput., vol. 22, no. 4, pp. 1397-1412, 2019.

[18] W. Muhamad, T. Wan, N. Laila, A. Ghani, and S. M. Drus, "Recent Trends in Data Science and Soft Computing," in A Study on Mobile Applications Developed for Children with Autism, 2019, vol. 843, no. January, pp. 40-46.

[19] M. A. Elaziz, S. Xiong, K. P. N. Jayasena, and L. Li, "Task scheduling in cloud computing based on hybrid moth search algorithm and differential evolution,” Knowledge-Based Syst., vol. 169, pp. 39-52, 2019.

[20] A. Rajagopalan, D. R. Modale, and R. Senthilkumar, "Optimal Scheduling of Tasks in Cloud Computing Using Hybrid Firefly-Genetic Algorithm," in International Conference on Emerging Trends in Engineering, 2029, vol. 4, no. Vm, pp. 678-687.

[21] C. Jatoth, G. R. Gangadharan, and U. Fiore, "Optimal fitness aware cloud service composition using modified invasive weed optimization," Swarm Evol. Comput., vol. 44, no. March 2018, pp. 1073-1091, 2019.

[22] S. H. H. Madni, M. S. A. Latiff, J. Ali, and S. M. Abdulhamid, "Multi-objective-Oriented Cuckoo Search Optimization-Based Resource Scheduling Algorithm for Clouds,” Arab. J. Sci. Eng., vol. 44, no. 4, pp. 3585-3602, 2019.

[23] S. H. H. Madni, M. S. Abd Latiff, S. M. Abdulhamid, and J. Ali, "Hybrid gradient descent cuckoo search (HGDCS) algorithm for resource scheduling in IaaS cloud computing environment," Cluster Comput., vol. 22, no. 1, pp. 301-334, 2019.

[24] K. Pradeep and T. Prem Jacob, "A Hybrid Approach for Task Scheduling Using the Cuckoo and Harmony Search in Cloud Computing Environment,” Wirel. Pers. Commun., vol. 101, no. 4, pp. 2287-2311, 2018.

[25] D. Kesavaraja and A. Shenbagavalli, "QoE enhancement in cloud virtual machine allocation using Eagle strategy of hybrid krill herd optimization,” J. Parallel Distrib. Comput., vol. 118, pp. 267-279, 2018.

[26] A. N. Jethava and M. R. Desai, "Optimizing multi objective based dynamic workflow using ACO and black hole algorithm in cloud computing," in Proceedings of the 3rd International Conference on Computing Methodologies and Communication, ICCMC 2019, 2019, no. Iccmc, pp. 1144-1147.

[27] A. Fathima and K. Vaidehi, "Advances in Decision Sciences, Image Processing, Security and Computer Vision," in ICETE, 2020 , vol. 4, no. Vm, pp. 608-618.

[28] K. Karthikeyan et al., "Energy consumption analysis of Virtual Machine migration in cloud using hybrid swarm optimization (ABCBA),” J. Supercomput., pp. 1-17, 2018.

[29] B. Gomathi, K. Krishnasamy, and B. Saravana Balaji, "Epsilon-fuzzy dominance sort-based composite discrete artificial bee colony optimisation for multi-objective cloud task scheduling problem,” Int. J. Bus. Intell. Data Min., vol. 13, no. 1-3, pp. 247-266, 2018.

[30] D. Gabi, A. S. Ismail, A. Zainal, Z. Zakaria, and A. Abraham, "Orthogonal Taguchi-based cat algorithm for solving task scheduling problem in cloud computing," Neural Comput. Appl., vol. 30, no. 6, pp. 1845-1863, 2018.

[31] N. Gobalakrishnan and C. Arun, "A new multi-objective optimal programming model for task scheduling using genetic gray Wolf optimization in cloud computing," Comput. J., vol. 61, no. 10, pp. 1-14, 2018.

[32] A. M. Manasrah and H. B. Ali, "Workflow Scheduling Using Hybrid GA-PSO Algorithm in Cloud Computing," Wirel. Commun. Mob. Comput., vol. 2018, pp. 1-16, 2018.

[33] Anu and A. Singhrova, "Prioritized GA-PSO algorithm for efficient resource allocation in fog computing," Indian J. Comput. Sci. Eng., vol. 11, no. 6, pp. 907-916, 2020. 